\title{
Development of a
}

\section{Practical Modeling Framework}

for Estimating the Impact of

Wind Technology on

\section{Bird Populations}

Michael L. Morrison

California State University

Sacramento, California

Kenneth H. Pollock

North Carolina State University

Raleigh, North Carolina

NREL technical monitor: Karin Sinclair

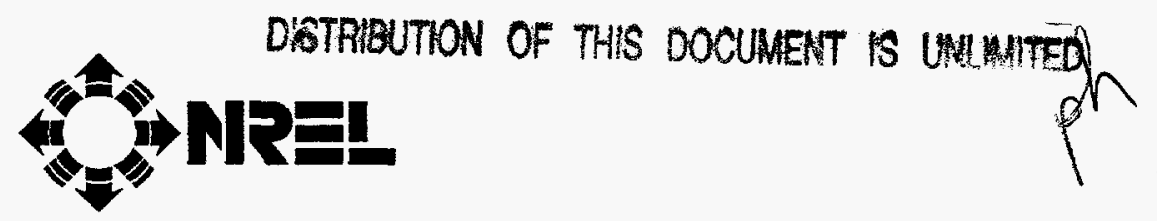

National Renewable Energy Laboratory

1617 Cole Boulevard

Golden, Colorado 80401-3393

A national laboratory of the U.S. Department of Energy

Managed by Midwest Research Institute

for the U.S. Department of Energy

under contract No. DE-AC36-83CH10093

Work performed under Subcontract No. CCD-5-15367-01

November 1997 


\section{NOTICE}

This report was prepared as an account of work sponsored by an agency of the United States government. Neither the United States govemment nor any agency thereof, nor any of their employees, makes any warranty, express or implied, or assumes any legal liability or responsibility for the accuracy, completeness, or usefuiness of any information, apparatus, product, or process disclosed, or represents that its use would not infringe privately owned rights. Reference herein to any specific commercial product, process, or service by trade name, trademark, manufacturer, or otherwise does not necessarily constitute or imply its endorsement, recommendation, or favoring by the United States government or any agency thereof. The views and opinions of authors expressed herein do not necessarily state or reflect those of the United States government or any agency thereof.

Available to DOE and DOE contractors from:

Office of Scientific and Technical Information (OSTI)

P.O. Box 62

Oak Ridge, TN 37831

Prices available by calling (423) $576-8401$

Available to the public from:

National Technical Information Service (NTIS)

U.S. Department of Commerce

5285 Port Royal Road

Springfield, VA 22161

(703) $487-4650$ 
DISCLAMMER

Portions of this doevoment may be illegible in electronic inage products. Images are produced from the best availabie original docementert 


\section{Foreword}

One of the most pressing environmental concerns related to wind project development is the potential for avian fatalities caused by the turbines. In order to understand the potential for this problem, pre-construction avian surveys are often required. However, these can be expensive and require significant amounts of time in order to gather the empirical data necessary to fully understand the potential impacts. Then, the results may suggest that moving forward with such a project in the wind resource area just evaluated may be ill advised. This report describes a modeling framework for evaluating potential windplant impacts that can be generalized to most bird species. This modeling framework could be used to get a preliminary understanding of the likelihood of significant impacts to birds in a cost-effective way.

Drs. Morrison and Pollock produced this report under a subcontract with the National Wind Technology Center of the National Renewable Energy Laboratory, with funding from the Wind Program at the U. S. Department of Energy.

\footnotetext{
Karin C Sinclais

National Wind Technology Center

National Renewable Energy Laboratory

1617 Cole Boulevard

Golden, Colorado 80401

Internet Address: karin_sinclair@nrel.gov

Phone: 303 - $384-6946$

Fax: $303-384-6901$
} 


\section{EXECUTIVE SUMMARY}

The goal of this project is to develop a useful, practical modeling framework for evaluating potential wind power plant impacts that can be generalized to most bird species. We accomplish this by (1) reviewing the major factors that can influence the persistence of a wild population; (2) briefly reviewing various models that can aid in estimating population status and trend, including methods of evaluating model structure and performance; (3) reviewing survivorship and population projections; and (4) developing a framework for using models to evaluate the potential impacts of wind development on birds.

We begin with a review of demography. Demography is the study of population statistics, including births, deaths, immigration, and emigration. From demography, we know that conditions leading to extinction are most likely to occur in small populations. Demographic rates vary because individuals do not sunvive for the same length of time, individuals vary in the number of offspring they bear, individuals often have low birth rates, and so forth. Adult survivorship is usually very high, especially in long-lived species (such as raptors). Therefore, estimating adult survivorship tells one a lot about population status. In addition, in most monogamous species, it is female survivorship that is most important to population persistence. At a minimum, then, quantifying adult survivorship provides a preliminary, basic indication of the status of the population. Modeling genetics is not likely to be as important as modeling demographic and ecological processes in evaluating population persistence. This is based, in part, on the lack of our sufficient understanding of genetics to use it as a basis for management. Thus, practical considerations were the overriding factor in this conclusion. Still, genetics may be a priority in small, isolated populations.

Random environmental events such as catastrophic fires, hurricanes, and disease can also have pronounced effects on small populations. Such factors can also have pronounced effects on large populations that are spatially divided into subpopulations. Here, factors such as dispersal will determine the fate of a subpopulation driven to very low numbers, or even to extinction, by a catastrophic event. Thus, the relative importance of environmental stochasticity must be based on an understanding of the spatial distribution of the population under study.

Next we review the parameters necessary to develop rigorous population-projection models. Life-history parameters are essential components of population-projection models. The characteristics that we collectively call life-history parameters of animals include quantifiable longevity, lifetime reproductive output, the young produced per breeding attempt, the age of dispersal, survivorship, sex ratio, and the time between breeding attempts. For example, combining various ranges of parameters can yield substantially different rates of population change. Such analyses provide guidance on whether the population can be sustained under varying expressions of life history traits. Once such relationships are understood, researchers have the opportunity to monitor selected life history traits as part of an assessment of the status of a population.

A central part of impact assessment--such as in wind power plants-is developing a model that estimates the survival rates required to maintain a constant population. The strategy is to determine the survival rates required to sustain the populations that exhibit the various combinations of the other parameters governing population size. To be useful in a wide range of environmental situations and useable for people with varying expertise, the model should be based on simple mathematics.

Leslie matrix and similar stage-structured models can give great insight into the processes of population growth. For example, the sensitivity of the population growth rate, $\underline{r}$, to perturbations 
in vital rates for a Leslie-type model can be solved analytically. Understanding how growth rate changes in response to perturbations at various stages in the life table may help direct management strategies. For example, adult survival tends to be a parameter to which a model is extremely sensitive in long-lived species, whereas fecundity can be more important in short-lived species.

To aid in providing general guidelines concerning the potential impacts of wind developments on bird populations, we developed Leslie matrix models and conducted sensitivity analyses to determine the effects of survival of age classes on population growth rates. We gathered data from the literature on passerines, ducks, geese, gulls, and eagles. These analyses provide a first approximation of how populations of these types of birds respond to hypothetical changes in fecundity and survivorship. They can be used to help focus attention on species most likely to be adversely affected by changes in fecundity and survivorship.

The simplest models assume that the number of animals in a population goes up or down by a constant ratio, usually designated as lambda, with each unit of time. The annual geometric growth rate of a population is thus represented by lambda, which is also known as the finite rate of population increase. The population is increasing if lambda $>1$, is constant if lambda $=1$, and is decreasing if lambda $<1$. For example, if lambda $=1.04$, then the population was growing at the rate of $4 \%$ during the time period sampled.

With the models in place, each survival rate parameter was allowed to vary from zero to one while the remaining parameters were held constant. The new value of lambda was calculated at each new value of the changing parameter. Once these data were obtained for each survival parameter, the results were plotted on a graph so as to see the different effects each parameter had on the population growth rate. This can be viewed as a way of expressing the sensitivity of lambda to the different survival parameters.

The curves for the passerine show that lambda is much more sensitive to changes in the juvenile survival rate than to changes in the adult survival rate. Also, the juvenile survival rate curve has a very steep slope as the juvenile survival gets very small. The curves for the duck show that lambda is roughly equally sensitive to changes in the juvenile and adult survival rates. For geese, the nonadult age classes survival rates seem to have little impact on the value of lambda. For the adult age class, lambda is extremely sensitive to changes in the adult survival rate. For gulls, except for very small survival rates, the changes in the adult age class gives the largest change in lambda. The other classes all have very similar curves. The situation for the eagle is very similar to the situation for the gull, but even more extreme: there is great sensitivity of lambda to changes in adult survival rate.

One of our objectives was to evaluate the use of surrogates, or indices, of survival and population trends. We found a highly significant negative relationship between adult survival and annual fecundity. This analysis indicates that fecundity might be a suitable surrogate for survival in passerines and woodpeckers. This does not imply, however, that fecundity is a suitable indicator of abundance (i.e., increasing fecundity does not necessarily compensate for lower survival). Raptors will leave poor habitat (e.g., low food availability), often moving many kilometers in search of a suitable nesting site. In addition, raptors tend to change territories more often when nesting is unsuccessful. Thus, as a generality, constancy of territory occupancy seems to be an indicator of good habitat quality in raptors. The number of nonbreeding, adult "floaters" in an area is an indicator of the general health of the bird population. This holds if territory availability is constant or increasing. Additionally, an increase in the age of first breeding, as well as an increase in adult aggression, are possible indicators of a population at or above carrying capacity. In long-lived species with delayed age at first breeding, such as in many raptors and some waterbirds, changes in survival rates have a greater effect on the 
population than changes of similar magnitude in reproductive rates. Thus, the use of reproductive success in long-lived species as a population indicator should likely be supplemented with other indicators, such as territory occupancy and floater individuals. The use of surrogates that we recommend here is not designed to determine the cause of population change. Rather, surrogates are intended to only identify that change has occurred; whether or not such change is caused by wind development will usually require more rigorous research (e.g., field work and experimentation). Surrogates serve primarily as a coarse filter to help narrow the scope of subsequent research.

We also present a series of steps that can be used to develop a strategy for evaluating the influence of a project on a bird population. Based on our review it seems that the appropriate hierarchial framework for evaluating population responses to perturbations is: (1) empirical data, (2) surrogates, and (3) model with available data (Leslie matrices). A large set of empirical data is, of course, the optimal situation. 


\section{Table of Contents}

$\begin{array}{ll}\text { Problem Statement } & 1\end{array}$

Development of Conceptual Framework 1

Demography 2

Genetics 3

Environmental Stochasticity $\quad 3$

Life History $\quad 3$

Ecological Factors $\quad 4$

Models

Introduction

Life Tables

Simple Lotka Models

Leslie Matrix Models

Effective Population Size

Population Viability Analysis

Model Evaluation

Objectives

Model Description

Analysis of Model Reliability 12

Model Structure $\quad 12$

Parameter Values $\quad 12$

Primary Prediction of the Model $\quad 12$

Synthesis

Secondary Predictions of the Model 13

$\begin{array}{ll}\text { Survivorship and Population Projections } & 13\end{array}$

Model Development: Examples for Wind-Development Applications 17

Results

Passerines $\quad 18$

Ducks 18

Geese 18

Gulls 18

$\begin{array}{ll}\text { Eagles } & 18\end{array}$

$\begin{array}{ll}\text { Surrogates } & 24\end{array}$

Conclusions: Development of An Analytical Framework 25

Hierarchical Framework $\quad 25$

$\begin{array}{ll}\text { Prioritization } & 26\end{array}$

$\begin{array}{lr}\text { Acknowledgments } & 27\end{array}$

$\begin{array}{ll}\text { Literature Cited } & 28\end{array}$

Additional Readings $\quad 32$ 
List of Figures

Figure 1. Relationship Between Nest Productivity and the Population Trend of Bald Eagle Populations

16

Figure 2. Sensitivities of Lambda to Different Survival Parameters in Selected Groups of Birds - Passerines

19

Figure 3. Sensitivities of Lambda to Different Survival Parameters in Selected Groups of Birds - Ducks

20

Figure 4. Sensitivities of Lambda to Different Survival Parameters in Selected Groups of Birds - Geese

21

Figure 5. Sensitivities of Lambda to Different Survival Parameters in Selected Groups of Birds - Gulls

22

Figure 6. Sensitivities of Lambda to Different Survival Parameters in Selected Groups of Birds - Eagles

23

viii 


\section{Problem Statement}

Evaluating the possible impacts of existing or proposed wind developments on bird populations is a continuing challenge. Although methods are available for making empirically-based estimations of potential impacts, they usually require intensive sampling over a number of years for each species of concern; the cost of such studies can be prohibitive. Given these difficulties, it would be desirable to develop a protocol that could provide at least a preliminary indication of the potential responses of birds and bird populations to wind developments.

One method with a high potential for estimating the impacts of a technology on a bird population is developing a model of that population over time. Such a model would include parameters that would represent the impact of that technology on the birds. Then, by changing parameter values, a first-order (i.e., initial) approximation of the impact of the technology would be obtained. This approach parallels what is done to gain insight on plagues or medical advances in human populations.

The goal of this project is to develop a useful, practical modeling framework for evaluating potential wind-farm impacts that can be generalized to most bird species. We accomplish this by (1) reviewing the major factors that can influence the persistence of a wild population; (2) briefly reviewing various models that can aid in estimating population status and trend, including methods of evaluating model structure and performance; (3) reviewing survivorship and population projections; and (4) developing a framework for using models to evaluate the potential impacts of wind development on birds.

\section{Development of Conceptual Framework}

The problem confronting the wind industry and society at large regarding potential impacts on birds falls under the general classification of environmental impact assessment. Determining the effects of an existing development on birds, or predicting the impacts of a planned development, is difficult. Thus, the problem confronting the wind industry is similar to that confronting virtually any planned development (e.g., residential or commercial building, power plants, recreational development). The goal in such studies is to determine the effects of specific management actions on individuals and/or populations that occur on a given site.

Managers need a framework for examining the various environmental costs associated with the different options they have available to them. In most cases, regulations require that an environmental impact analysis be developed. The federal National Environmental Policy Act of 1969 (NEPA), which includes the environmental impact assessment (EIA)/environmental impact statement (EIS) process, is designed to review the likely impacts a proposed development will have on the biotic and abiotic environment in the project area. Unfortunately, no consensus exists on the type, quality, and amount of data that are necessary to develop a sound environmental analysis. Further, even if such a consensus existed, it is unlikely that the biological information necessary to develop a sound analysis would be available in the scientific literature.

Therefore, managers and researchers alike have been exploring the options available to them to foster the development of rational decisions. One requirement of any modeling process is clear elucidation of the information needed to make a decision, and, further, a detailed description of the strengths and weaknesses of each category of data. This is necessary because certain categories of data will have a greater influence on the validity of the conclusions than other categories, and not all categories will have the same quality and amount of data available. Such a process falls under the general heading of decision analysis, an approach that allows 
examination and comparison of expected benefits and costs among various management options (Lindenmayer et al. 1993).

Making determinations of likely environmental effects is difficult because of the complex interactions present in any biological system, the difficulties in determining the proper spatial and temporal scales for analysis, and the inherent lack of data for most parts of a biological system. Federal management agencies have adopted various strategies to formalize NEPA requirements and other federal laws (e.g., Endangered Species Act [ESA]). The U.S. Fish and Wildlife Service, for example, develops recovery plans for threatened and endangered (T\&E) species under ESA. These plans include a cletailed review of the available published and unpublished data to arrive at management plans that are designed to "recover" the species from the T\&E list. The U.S. Forest Service has developed a formal "biological evaluation" procedure wherein biologists provide written documentation of their judgement about whether or not a proposed management action will increase the likelihood of the species of concern becoming threatened or endangered (modeling is not required). These judgements are formalized in a "determination of effect" document (Ruggiero et al. 1994).

A severe and continuing problem in ecology and management is determination of the relevant population of study. A typical definition of population illustrates the vagueness of the concept: a population is a group of organisms of the same species living in a particular space at a particular time (Krebs 1985). A population is quantified in terms of birth rate, death rate, sex ratio, emigration-immigration, and age structure. Unfortunately, the absolute values for each of these parameters is determined in large part by the boundaries the user draws. Recently, much interest has developed in understanding the role that the spatial structure of a population has on genetics, and ultimately, survival. A metapopulation is composed of many subpopulations. This concept relates directly to determinating the impacts on animals. First, even impacts occurring in a small geographic area can disrupt immigration and emigration between local subpopulations, and thus the impact can have a much wider effect on the population than immediately evident. Second, small impacts can have serious consequences to the persistence of small populations if population size is allowed to drop below a certain threshold level (e.g., the effective population size).

Below we review the major factors that can influence the persistence of a population. These factors must be considered when developing a study plan for evaluating the potential impacts of developments.

\section{Demography}

Demography is the study of population statistics, including births, deaths, immigration, and emigration. Conditions leading to extinction are most likely to occur in small populations because individuals do not survive for the same length of time, individuals vary in the number of offspring they bear, individuals often have low birth rates, and so forth. Such effects are sensitive to population size, and their influences decline as population size increases. Larger total sample sizes are needed, however, if the population is effectively divided into many local subpopulations (which is likely in the case of birds with regard to wind development). At low densities, a threshold or critical population size can exist below which extinction is probable. For example, limitations to juvenile dispersal can create an extinction threshold in territorial species (Lande 1987).

Partitioning a model into spatial subunits can be difficult to model, although an increasing desire for understanding metapopulation dynamics is forcing such efforts (e.g., Wootton and Bell 1992). Spatial heterogeneity and dispersal can stabilize population fluctuations, whether the fluctuations are caused by natural or human-induced factors. Unfortunately, no general statements can be 
made regarding the influence of corridors; minimum distances between habitat patches; or the ability of dispersers to locate suitable areas; the size and shape of suitable habitat patches; the ability of animals to travel across, or survive within, marginal habitats. Quantifying emigration and immigration is an important, but problematic, aspect of research needs.

Adult survivorship is usually very high, especially in long-lived species (such as raptors). Therefore, estimating adult survivorship tells one a lot about population status (Lande 1988). In addition, in most monogamous species, it is female survivorship that is most important to population persistence (e.g., Wootton and Bell 1992). At a minimum, then, quantifying adult survivorship provides a preliminary, basic indication of the status of the population.

\section{Genetics}

Models of genetic variation have a central role in the conservation of populations. This is because of the interest in how small population size results in more inbreeding among related individuals and a concomitant reduction in genetic variation, both of which can lead to extinction (Boyce 1992). However, local subpopulations may contain the genetic diversity that is necessary to ensure survival of the species if individuals from such subpopulations occasionally meet and breed with each other.

Boyce (1992) concluded that modeling genetics is not likely to be as important as modeling demographic and ecological processes in evaluating population persistence. He based this conclusion, in part, on the lack of our sufficient understanding of genetics to use it as a basis for management. Thus, practical considerations were the overriding factor in his conclusion. Still, genetics may be a priority in small, isolated populations.

\section{Environmental Stochasticity}

Random environmental events such as catastrophic fires, hurricanes, and disease can have pronounced effects on small populations. Such factors can also have pronounced effects on large populations that are spatially divided into subpopulations. Here, factors such as dispersal will determine the fate of a subpopulation driven to very low numbers, or even to extinction, by a catastrophic event. It is also important to understand the variance structure of the population; that is, how does environmental stochasticity affect the individuals differently. A major problem here, however, is that the difficulties of sampling a variance adequately may overwhelm any attempts to decompose a variance into individual and environmental components. Thus, the relative importance of environmental stochasticity must be based on an understanding of the spatial distribution of the population under study.

\section{Life History}

The characteristics that we collectively call life-history parameters of animals include quantifiable longevity, lifetime reproductive output, the young produced per breeding attempt, the age of dispersal, survivorship, sex ratio, and the time between breeding attempts. The absolute expression of each of these characteristics is usually determined by the age of the individual; thus they change during the lifetime of an animal. For example, young and old individuals tend to produce fewer viable young than do animals in their prime. In addition, these factors can interact in various ways that modify the expression of other factors.

Life-history parameters are used in the development of population-projection models. For example, combining various ranges of parameters can yield substantially different rates of population change. Such analyses provide guidance on whether the population can be sustained under varying expressions of life history traits. Once such relationships are understood, 
researchers have the opportunity to monitor selected life history traits as part of an assessment of the status of a population. For example, if previous work shows that the timing of breeding is correlated with reproductive output, and thus with the population size for the year, monitoring the time of breeding can provide an early warning of potential population-level problems.

Naturally, this is a simplistic view of the numerous factors that determine population size and trend. However, it illustrates the utility of developing even rudimentary models as part of the evaluation of the population status. The data necessary for input into such models are often available in the literature (this topic is discussed in the Models section below).

\section{Ecological Factors}

Temple (1985) found that for birds currently endangered by extinction, $82 \%$ are associated with habitat loss, $44 \%$ with excessive take, $35 \%$ by introductions of exotics, and $12 \%$ by chemical pollution or the consequences of natural events. It is relatively easier to quantify and model habitat parameters and their influence on some index of population abundance and life-history traits, than it is to adequately quantily and model demographic parameters. However, it is difficult to evaluate the reliability or precision of these indices without some type of calibration with absolute values.

The weakness in ignoring demographics is, of course, the likelihood that many of the abundancehabitat correlations will provide little information on why the correlation occurred. This is because habitat models usually reflect some indirect measure of the population's response to the actual underlying factor. For example, a negative correlation between animal abundance and canopy cover could be masking the fact that a predator is at high abundance under high cover.

Resolving the problem of variables interacting and thus confounding results is problematic; this problem has a long history in modeling of human disease processes. A detailed demographics study would likely discover that excessive mortality of the prey species is occurring. Competitors, parasites, and disease also influence populations in substantial ways that are ignored by most habitat-based analyses.

\section{Models}

\section{Introduction}

A central part of impact assessment is developing a model that estimates the survival rates required to maintain a constant population. The strategy is to determine the survival rates required to sustain the populations that exhibit the various combinations of the other parameters governing population size. To be useful in a wide range of environmental situations and useable for people with varying expertise, the model should be based on simple mathematics.

The use of models (of all types) has soared in the past 10 years. In fact, modeling is now a focus of much interest, research, and management action in wildlife and conservation biology. But as in all aspects of science, models have certain assumptions and limitations that must be understood before results of the models can be properly used. Modeling per se is neither "good" nor "bad"; it is the use of model outputs that determines the value of the modeling approach. Modeling requires that all terms be defined precisely. The process of thinking rigorously about the modeling framework is often the most useful product of a modeling exercise.

The use of population models to make management decisions is fairly common. For example, models play a role in management plans for such threatened and endangered species as the spotted owl (Strix occidentalis, all subspecies), desert tortoise (Gopherus agassizi), Kirtland's 
warbler (Dendroica kirklandii), and various kangaroo rats (Dipodomys spp). Models are valuable because they analyze the effects of management proposals in ways that are usually not possible using short-term data or professional opinion.

Two general uses of models can be distinguished: using models to give insight into how an ecological system behaves versus using models to predict specific variables. Both types of models help guide decisions when used in combination with other reliable data; and both should involve testing model assumptions and results in a quantitative manner (i.e., model validation).

\section{Life Tables}

Life tables are one of the oldest means of examining mortality in animals; simply, they summarize survivorship by age classes in a cohort of animals. Grier (1980) and Beuhler et al. (1991) used a deterministic life-table model to calculate survivorship and population growth in bald eagles (Haliaeetus leucocephalus).

There are, however, many limitations to using life tables in analyzing wildlife populations. A basic life table requires only that age, the number of individuals surviving to the beginning of each age classification, and the number of deaths in each age class be known; mortality and survival rates can be calculated from these data. There is only one independent column in a life table; all the others can be calculated from entries in any one column. This dependency requires that great care be taken in constructing the table, and that large sample sizes be gathered. Other restrictive assumptions include: (1) Fecundity and mortality are assumed to be unaffected by population density and to be time invariant (i.e., stationary with regard to time). (2) Reproductive success of females is assumed to be unaffected by the number of breeding males. (3) All individuals are assumed to be subject to the same fecundity and mortality schedule. These assumptions are usually violated, which renders results suspect. It is also difficult to estimate parameters from life tables (Caughley 1977, Getz and Haight 1989). These parameters are discussed in the next section.

\section{Simple Lotka Models}

The simplest Lotka model assumes that the number of animals in a population goes up or down by a constant ratio, usually designated as lambda, with each unit of time. The annual geometric growth rate of a population is thus represented by lambda, which is also known as the finite rate of population increase. At time $\underline{t}$ the population size is lambda times population size time $\underline{t}-1, \underline{N}$ $=$ lambda $\left(\underline{N}_{t .1}\right)$. The population is increasing if lambda $>1$, is constant if lambda $=1$, and is decreasing if lambda $<1$. For example, if lambda $=1.04$, then the population was growing at the rate of $4 \%$ during the time period sampled. For purposes of calculation, this formula is usually presented as $\underline{N}_{t}=\underline{N}_{-1} e^{r}$, where $e$ is the base of natural logarithms, and $\underline{r}$ is the instantaneous rate of population increase (Johnson 1994).

Lambda should be viewed like any other impact indicator. That is, it is difficult to attribute a change in lambda to treatment (impact) effect without control areas. Lambda seems most useful in evaluating the overall status of the population, rather than as a means of isolating the cause of that status (i.e., increasing, decreasing, or stable). This is because there may be many environmental factors that have a substantial influence on population status (e.g., weather, pollution, food availability, disease, predators).

Eberhardt (1990) developed a modeling scheme based on approximations of the Lotka equations using the grizzly bear (Ursus arctos) as an example. The parameters used to develop the model included the litter size, proportion of female cubs, breeding interval in years, and reproductive rate. The utility of this approach was that estimates of these parameters were available in the 
literature. Eberhardt used variations among these estimates (e.g., litter size ranged from 1.65 to 2.36) to calculate ranges of female survival rates to provide information about the scope of such rates needed to sustain populations. Each user of the Eberhardt scheme could select the particular combination of demographic parameters thought to be most appropriate for a particular situation. The Eberhardt procedure is, of course, only as good as the empirical estimates used as model input.

Given any age-specific survival rate, and assuming a stable age distribution, we can estimate the average productivity that must exist in order that the population remains at a constant size. Henny et al. (1970), for example, categorized species that had similar breeding strategies and presented different formulas applicable to each group. They provided the production needed per breeding-age female for a stable population to be maintained as well as the age ratio that indicated a stable population. Their "special cases" can be summarized as follows:

1. For an animal that reproduces young at the end of its first year and which has a constant survival rate after the second year. Most species of birds fall into this category, including the Passeriformes, many clucks and gamebirds, and shorebirds; included in the calculations were the American coot (Fulica americana), green-winged teal (Anas crecca), canvasback (Aythya valisineria), redhead (Aythya americana), ring-necked pheasant (Phasianus colchicus), and house sparrow (Passer domesticus).

2. For an animal that produces young for the first time at the end of the second year. Many diving ducks, geese, hawks, owls, and herons were in this category; included in the calculations were the great-horned owl (Bubo virginianus), herons, and snow goose (Chen caerulescens).

3. For an animal that produces young for the first time at the end of the third year. Some raptors and waterbirds fall into this category; included in the calculations were the Caspian tern (Sterna caspia) and osprey (Pandion haliaetus).

Henny et al. (1970) also provided directions on calculating the "allowable mortality for maintenance of a stable population level". The difficulty in their approach, of course, is obtaining precise survival estimates. Henney et al. did state, however, that obtaining a 5-year average or precise survival estimates periodically (e.g., once every 5 years) should be adequate in most situations (i.e., non-endangered populations). Additionally, they assume that the age distribution is stable. Although this assumption likely holds in the short term, changes in the age distribution is often symptomatic of either an increasing or decreasing population size. Further, they assume a constant survival rate after breeding age is obtained. Fortunately, this appears to hold for most animals (although survival decreases as senescence is approached). The Henny et al. (1970) procedure offers a relatively simple means of at least estimating the status of a population; large departures from stability would indiciate that further study is warranted to verify the situation.

\section{Leslie Matrix Models}

Leslie matrix and similar stage-structured models (Caswell 1989) can give great insight into the processes of population growth. For example, the sensitivity of the population growth rate, $\underline{r}$, to perturbations in vital rates for a Leslie-type model can be solved analytically (although potentially severe limitations exist, which are discussed below). Understanding how growth rate changes in response to perturbations at various stages in the life table may help direct management strategies. For example, adult survival tends to be a parameter to which a model is extremely sensitive in long-lived species, whereas fecundity can be more important in short-lived species.

Matrix models subsume classical life table analysis as a special case but have capabilities that 
go far beyond that analysis. As summarized by McDonald and Caswell (1993), they (1) are not limited to classifying individuals by age; (2) they lead easily to sensitivity analysis; (3) they can be constructed using the life cycle graph, an intuitively appealing graphical description of the life cycle; and (4) they can be extended to include stochastic variation and density-dependent nonlinearities. Caswell (1989) presents the theory of these models and McDonald and Caswell (1989) present a detailed description of the formulation and application of matrix models to avian demographic studies (see also Lebreton and Clobert 1991).

The numbers in the body of the matrix are transition probabilities for survival and progression into other stages, while the numbers on the top row of the matrix represent stage-specific fecundity values (see Shenk et al. 1996). A Leslie matrix can be built from estimates of fecundity and survival probabilities, and population growth may be projected for any number of time periods by pre-multiplying the age distribution at each time period by the Leslie matrix to get the new age distribution for the next time period. Thus, we term this matrix the population projection matrix, or more popularly, the Leslie matrix after its developer (Leslie 1945).

Population projections using Leslie matrices are a useful approach to the analysis of demography (Jenkins 1988). They provide a numerical tool for determining growth rate and age structure of populations. They are also useful for illustrating and studying the transient properties of populations as they converge to the stable state.

Stage-based matrices (e.g., Lefkovitch models), analogous to the age-based Leslie, can be used to analyze population growth for species in which it is difficult to age individuals, or where it is more appropriate to classify them into life stages or size classes rather than by age; these models are generally referred to as Lefkovitch (1965) stage-based models. It is extremely difficult to determine the specific age of most birds and mammals after they reach adulthood. In the case of raptors-the focus of concern in many wind developments-young and subadults can usually be aged up until adulthood (through differences in plumage and soft tissues, and sometimes eye color). Further, adult raptors can often be placed into categories based on breeding status.

Lefkovitch models assume a single, well-mixed population with no spatial structure and no density dependence in the variables. Thus, they assume homogeneous probabilities of survivorship and breeding success within each stage, independent of other factors such as age. The models can be modified to incorporate spatial population structure and analyze this structure in the context of different management options for a population (e.g., see Wootton and Bell 1992 for development and review). Building models that include dispersal, for example, is not technically difficult; spatial cells can be constructed that have the same status mathematically as age classes. In addition, these can be developed in both density-independent and densitydependent cases (Lebreton and Clobert 1991). The problem with building spatially relevant models, however, is obtaining reliable empirical data on the movements of individuals in a real population. Although demographic stochasticity may be negligible in large, homogeneous populations, it could be considerable in smaller, subdivided populations.

An example of a Lefkovitch stage-based model is being developed to assess the impact of the Altamont Wind Resource Area on the resident golden eagle (Aquila chrysaetos) population (see Shenk et al. 1996 for modeling details). The model is being developed by a team of scientists assembled by NREL; field data are being collected by Dr. Grainger Hunt, who is also assisting in model development. The overall goal of the project is to determine the finite rate of population growth (lambda) based on birth and death rates for the defined golden eagle population around the WRA. If the estimate of lambda is $>1$, then the population will be assumed to be stable or increasing. If lambda is $<1$, then no definite conclusion regarding the impact of the WRA on the population can be made. Because of the lack of a controlled experiment, there could be many 
reasons for a declining growth rate; however, it would suggest very detailed field studies should be done. The model may, however, provide a quantitative understanding of the current status of the eagle population. Further, parameter estimates of survival and fecundity will assist in evaluating the status of the population through comparisons with the same information for other populations. Thus, the approach selected combines a model-based approach with field data (design-based approach).

The group developing the Altamont piopulation model were faced with time (2-3 years for field study) and monetary constraints. Because of these constraints, time effects will have to be ignored (i.e., they cannot determine interyear variability), and sampling must focus only on those elements essential to model development.

The modeling group has also evaluatted the sample sizes necessary to estimate the survival rate with a minimum precision of $10 \%$. The eagle population can be broken into four general categories: adult breeders (territory holders $>4$ years old); adult floaters (non-territory holders $>4$ years old); subadults (1-4 years old); and juveniles ( $<1$ year old). Eight total categories resulted when sex was considered. Preliminary analyses indicated that at least 25 individuals would be necessary for each of the eight classes. Based on time and funding constraints, it was infeasible to sample that many individuals. Further discussion indicated that all adult floaters and subadults could be combined and considered "nonterritory holders". Although telemetry is being used to determine survival, there was not enough time or funding to quantify immigration and/or emigration. Therefore, immigration and emigration were assumed to have no influence on lambda. This assumption, if incorrect, could have substantial ramifications on interpretations of model output. As such, studies of immigration-emigration should be a high priority addition in follow-up studies. The assumptions and constraints necessary in the Altamont eagle study are, however, typical of real-world modeling situations, and do not negate the value of a modeling exercise.

\section{Effective Population Size}

As discussed above, small populations are susceptible to extinction because of the random loss of genetic variation. In the "ideal" theoretical population, the rate of loss of variation is inversely proportional to the population size. Of course, the reproductive behavior of natural populations is far from ideal. To link natural and idealized populations, Wright (1931) defined the "effective population size" $\left(\underline{N}_{e}\right)$ as the size of an ideal population whose genetic composition is influenced by random processes in the same way as the natural population.

When $\mathrm{N}_{\mathrm{e}}$ is small, the population can rapidly loose genetic variation. However, $\mathrm{N}_{e}$ has no set relationship to actual population size, and its precise estimation is complex. Two approaches have been used to estimate $\underline{N}_{e}$ : genetic and ecological. The genetic methods directly quantify the effects on genetics of a particular effective population size, whereas the ecological methods are indirect and depend on the measurement of ecological parameters that are thought to influence a particular effective population size.

There are several problems associated with determinating the (direct) effective population size by a genetic method. First, the method requires gathering large amounts of genetic information. Although new technologies are reducing this problem, it is still beyond the capabilities of most researchers. Second, the confounding factors of immigration and population subdivision and the possibility that even relatively low levels of some types of selection have a large influence on the estimated $\underline{\mathrm{N}}_{\mathrm{e}}$.

The indirect ecological methods depend on the theory linking particular ecological parameters, usually based on demography or behavior, to changes in $\mathrm{Ne}$. Wright (1938) established the 
relationship linking the effective population size to the population sex ratio and to the variance in reproductive success among individuals. For example, a variation in family size inflates the variance in reproductive success and thus reduces the effective population size.

Various formulas have been developed to estimate the effective population size. Harris and Allendorf (1989) evaluated several of these methods. Hill's (1972) original equation and its derivatives were consistently the most accurate. Nunney and Elam (1994) developed a related approach that required a minimum amount of information while still providing a good estimate of $\mathrm{N}_{\mathrm{e}}$. Termed the "minimal" method, it requires the estimation of six parameters: (1)the mean maturation time to adulthood for both males and females; (2)the mean adult life span for each sex; (3) the estimation of generation time; estimation of variation in the (4) male and (5) female reproductive success per breeding season; and (6) an estimation of the adult sex ratio. This method is designed to provide an estimate of the effective population size in long-lived populations by using the minimum data possible derived from the literature and short-term study. The method is most effective if survivorship is age-independent, which is common in many natural, long-lived populations (not including juveniles).

Nunney and Elam (1994) argued that the minimal method (and ecological methods in general) provide data that can be used to predict changes in effective population size as the conditions confronting the population change. Thus, it functions well in monitoring populations over time. Genetic methods determine what the effective population size has been over the last or several generations, but they provide no insight into why this has been the prevailing value. Therefore, they recommend ecological methods when it is practical, so that the effect of different management options on the effective population size can be estimated. They note, however, that the demographic information needed to provide a reliable estimate of $\mathrm{N}_{e}$ can often be difficult to obtain.

There has been continuing debate over the minimum population size necessary to maintain and ensure long-term persistence. During the 1980 s and into the $1990 \mathrm{~s}$, geneticists estimated that the minimum effective population size was $\mathbf{5 0 0}$ or so breeding individuals. New genetic evidence suggests, however, that this former estimate is far too low, and could easily range between 1,000 and 10,000 individuals. This new estimate is based on consideration of the effect that mutations have on the fitness of the organism at low population sizes (Lande 1995, Lynch et al. 1995). It is difficult to make broad generalizations on the effective population size of organisms. For example, small ( $<100$ adults) populations have been shown to persist for extended periods of time because of adaptations to local environmental conditions (e.g., Reed et al. 1986, Grant and Grant 1992, Nunney 1992).

\section{Population Viability Analysis}

A population viability analysis (PVA) is a complex process that considers all factors that affect the processes of a species' population dynamics (that can lead to extinction). Such factors can include demographic, genetic, and environmental stochasticity. Life history and habitat-use parameters, dispersal, competition, and predation may also need to be considered. By formally trying to understand these processes and how they might influence the species, our general knowledge of how an environmental change might impact the species is formed. The determination of biological effect made by the Forest Service (discussed above) in their biological evaluation procedure is usually based on some type of PVA.

Models are used within the PVA process, ranging from simple verbal to complex mathematical versions (as reviewed above). A PVA should thus be considered a "process" rather than a specific model in and of itself. It entails evaluation of available data and models for a population to anticipate the likelihood of population persistence over some period of time. The "minimum 
viable population" (MVP) modeling scheme, in which an estimate of the minimum number that constitutes a viable population is estimated, is closely related. PVA embraces MVP, but without seeking to arrive at an absolute population minimum. MVP can be considered in overall determination of the PVA.

There are few published or peer-reviewed PVAs, and most of those available provide only a vague outline of model structure or use general "rules of thumb" that are burdened with strong assumptions. There are no specific guidelines for completing a valid PVA. This is understandable, however, because each situation is unique because of differing environmental conditions and differences in the proposed impact(s). The advantage of the PVA is in the fact that sufficient data to derive reliable estimates for all parameters to develop a MVP is not practical in most cases (for the reasons developed above).

Hindering the wider use of PVAs in the decision-making process is a general misunderstanding of their strengths and limitations. Boyce (1992) and Lindenmayer et al. (1993) carefully reviewed this topic, with Boyce outlining the following strengths of a PVA: (1) it produces an explicit statement of the ecology of the species and identifies missing data; (2) it synthesizes interacting factors and identifies trends in population behavior; (3) it identifies processes threatening to the species; (4) it can be used in defining minimum critical areas and designing reserves; (5) it can enhance on-ground management arid decision making; and (6) it has applications in species recovery, reintroduction, and captive breeding programs. It is clear that PVAs have applicability in a wide range of management scenarios, which increases the need for managers from all disciplines to understand their functioning.

Of particular interest in the application of PVAs to wind development are Lindenmayer et al. (1993) points 1, 2, 3, and 5. By describing the general ecology of the species (point 1), users from all educational backgrounds are able to better understand the problems confronting the scientist in making predictions regariding likely environmental impacts of development. For example, the needs of a raptor for certain types and sizes of prey when feeding young, or the influence of a skewed sex ratio on territory occupancy during breeding, are complicated issues that must be described. These factors might interact (point 2) because only a certain sex is able to efficiently exploit the prey available in the project area; development might change this prey availability because of ground disturbance and changes in plant-species composition (point 3 ). Development of points 1-3 naturally leads to fulfillment of point 5 , namely enhancement of sound decision-making regarding both permitting of the project, and in the case where permitting is allowed, modification of the project to avoid potential impacts to the species of concern (in the above example, avoiding unwanted changes in prey availability through habitat management).

As noted by Lindenmayer et al. (1993), PVAs are only as strong as the data available for use in their development: "The more data the better for PVAs". And because all models are simplifications of ecological interactions, PVAs by their sheer complexity tend to inflate errors. Further, because of substantial differences in life-history parameters among species, no generic PVA model is available. This greatly complicates the use of a PVA, because one must be familiar both with the ecology of the species as well as a complex set of mathematical formulations (Lindenmayer et al. lists many of the models available). As such, most models for PVA analysis must be modified to meet the particular requirements of a given project.

The use of PVAs is thus hindered not by something inherently wrong with the concept per se, but rather by the inherent complexity of biological systems. PVAs are simply an attempt to formalize the complexity of nature. As such, PVAs greatly enhance decision-making by formally identifying the process under study; thus they provide a list of the data available and the data still needed to make a rational decision regarding project impacts. Researchers and managers alike are increasing their use of PVAs (Mace and Lande 1991). The use of PVAs are also limited by the 
fact that they are, at best, "what if" analyses. Few PVAs can be tested experimentally, given we would have to wait and see if, indeed, the population remained viable (i.e., it persists long term).

Boyce (1992) and Lindenmayer et al. (1993) reviewed many of the PVAs that have been constructed. The summary presented by Lindenmayer et al. (1993:Table 1) is especially useful in highlighting the fact that each of the PVAs they reviewed identified and estimated the primary cause of risk to the population. As they noted, habitat loss was the primary risk factor in most of the situations evaluated. In cases where habitat loss was not the primary factor, a species-and site-specific factor was identified as the primary concern. For example, hurricanes-which fall into the general category of environmental stochasticity-were the risk factor for several small, geographically isolated populations (e.g. Puerto Rican parrot [Amazona vittata] and key deer [Odocoileus virginianus clavium]). Other site-specific impacts were found to be the primary risk agent in other isolated populations, including ski resort development, hunting, and logging.

These results from the PVA are mostly intuitive to the biologist: one would expect that a small, isolated population would be negatively impacted by factors heavily impacting the location where members of the population remain. The ability of a population to adjust to changes in its habitat can be predicted through careful study of the behavior of individuals in the population; that is, through determination of the classification of individuals as either "specialists" or "generalists". By definition, habitat is a species- or population-specific phenomenon (Morrison et al. 1992). As such, changes to the habitat must have some impact on individuals in the area, given the habitat has been properly characterized by the researcher.

The question arises, then, if results of PVAs are biologically intuitive, what value does actual creation of a PVA offer? The answer is that by constructing a PVA, the researcher is able to check, in a systematic and analytical fashion, whether her or his intuition was indeed correct. Perhaps a proper test of a PVA would involve evaluating a hypothesis based on researcher knowledge and intuition. Further, a PVA allows knowledge to be gained on the interactions of various life-history parameters and their impact on population numbers.

\section{Model Evaluation}

Bart (1995) provided an excellent review of the steps necessary in evaluating the appropriate uses of a population model: the model objectives, a model description, and an analysis of model reliability. The latter component is further divided into four important criteria.

\section{Objectives}

All studies should list the specific objectives for which model outputs will be used and the reliability needed for those outputs. Will the output be used only as part of a much larger set of information, or will management decisions be based on model results? The precision needed should be specified.

\section{Model Description}

The general structure and organization of the model must be detailed. This description should include details such as the basis for classifying the environment (e.g., vegetation types used for analysis), the number of sex and age classes, and the behavior of the animals (e.g., breeding times and dispersal). For example, if sexes or age classes are lumped (because of sample-size considerations), then the behavior of the sexes and age classes is assumed to be equal.

Likewise, if data on any aspect of the model are lumped across years, then time is held constant and assumed to have no overriding impact on the model. Careful consideration and justification 
of any decisions must be included in model description because they will usually reduce the complexity and reality of the model.

\section{Analysis of Model Reliability}

There are four major types of model reliability to evaluate: structure, parameter values, primary predictions, and secondary predictions. Each type should receive attention, with emphasis on the particular type that the management will focus on.

\section{Model Structure}

The realism of each assumption should be fully assessed using any information available. Naturally, the first source of information is the scientific literature about animal behavior, habitat relationships, population structure, and demographics. If little information is available on the species of interest, then data on related species should be consulted. The impact that each assumption has on model results should be clearly discussed. Some assumptions will likely have minimal impact, while others may have potentially substantial influence on the model. In some cases, the decision will have to be made that insufficient information is available on this or closely related species for any meaningful evaluation of the model to be made. In such cases, the model-if developed-is of the purely descriptive form and should only function in identifying likely areas upon which field research (to fill the data gaps) should focus. However, usually enough information is available for at least a preliminary model structure.

\section{Parameter Values}

The most reasonable estimate of mean values, variances, and ranges for each parameter should be developed. The literature should first be consulted, but it is likely that field studies will have to be conducted to provide reasonable estimates of certain parameter values. Unfortunately, the wildlife literature provides little in the way of strong data on survivorship of animals, especially where data on specific sex-age classes are needed. The reality of the situation usually demands that a short-term (1-3 year) study be initiated to provide the missing data. Because we are usually interested in either rare species, or isolated populations, we often have to ignore yearly variations and lump across time to achieve an adequate sample size. The ramifications of this type of simplification must be carefully evaluated. In most animals, age cannot be readily determined after adulthood is reached, so it is also almost always the case that certain age classes (e.g., nonbreeding adults in raptors) will have to be combined.

\section{Primary Predictions of the Moclel}

Primary predictions are the outputs of primary interest used to make management decisions. Predicted model results should be compared to reality either by comparing them with empirical data or by running simulations (sensitivity analyses) that can be compared with known (past) population values. That is, if the model fits past (known) trends, then it is more likely to be properly forecasting future values. Unfortunately, little data are usually available because few species have been adequately studied. Most evaluations of models, however, are not truly independent. This is because available empirical data will likely have been used to initially develop the model; testing the model predictions with the same data results in a biased validation. Models should be tested with a new, independent data set collected at a different time and/or place.

Inferences drawn from the results of sensitivity analysis can be misleading and will not always indicate the best management actions. These analyses are best regarded as a guide for the 
allocation of sampling effort if the aim of measuring demographic parameters is to estimate the population multiplication rate (lambda)(Green and Hirons [1991]). Sensitivity analysis only establishes the effect of a fixed absolute change in a parameter value on the population multiplication rate.

\section{Secondary Predictions of the Model}

Secondary predictions are intermediate outputs of the model that can be used to better understand the population and help evaluate the reliability of the final model. Each of these outputs is a function of two or more input variables. Comparing them to empirical data, and to data for similar species, helps identify how reliable the model will be (and where weaknesses exist). Examples of secondary outputs include data such as the distribution of age classes at first breeding or territory occupation.

\section{Synthesis}

The goal should be to present a realistic and unbiased evaluation of the model. It is preferable to present both a best and worst case scenario for model outputs, so that the range of values attainable by the model can be evaluated. For example, with a basic Leslie Matrix Model of population growth, knowing whether the confidence interval for the predicted (mean) value for lambda (rate of population growth) includes a negative value provides insight into the reliability of the predicted direction of population growth.

The process of model development and evaluation may show that the predictions of the model are sufficiently insensitive (i.e. robust) to the existing uncertainties about the animal's behavior and demography so that high confidence can be placed in the model's predictions. Even a poor model does not mean that modeling is inappropriate for the situation under study. Rather, even a poor model (i.e., a model that does not meet study objectives) can provide insight into how a population reacts to certain environmental situations. It can thus provide guidelines as to how empirical data should be collected so that the model can be improved. Modeling is usually an iterative process.

\section{Survivorship and Population Projections}

We reviewed major wildlife and ornithological journals (e.g. Journal of Wildlife Management, Condor, Auk, and Journal of Raptor Research) published during the past 20 years to determine if any commonality existed among species with regards to annual survivorship. Most data in the articles examined were based on either short-term (usually 1-3 years) telemetry studies, or longterm analyses of band returns. Most of the band return data were obtained from waterfowl harvested by hunters.

In summary, only very broad generalizations can be drawn regarding "normal" survival rates of avian populations. Further, yearly variability in survivorship is large even in healthy populations, which makes short-term (1-2 years) evaluations of a population suspect. Bellrose (1980) summarized survival rates for waterfowl, concluding that immature ducks show $60-70 \%$ first year mortality, but that subsequent (adult) yearly loss is only $35-40 \%$ (or survival of about $60-65 \%$ ). More recent studies confirm Bellrose's general values. For example, Smith and Reynolds (1992) found that survivorship in mallards (Anas platyrhynchos) ranged from about 0.6 to 0.7 , and the population showed no decline in abundance during the study. Unfortunately, most studies that present survivorship data have no information on population trends or projected population persistence; most showed survivorship values similar to those summarized by Bellrose (1980; e.g., see Conroy et al. 1989, Chu et al. 1995, Reynolds et al. 1995). Haramis et al. (1993) and 
Hohman and Pritchert (1993) found what they called "high" survivorship rates of over $90 \%$ in canvasbacks. Arnold and Clark (1996) reported survival estimates of female dabbling ducks based on mark-resighting analyses: mallard (juv. $=0.55$, adult $=0.56$ ); galdwall (Anas strepera; adult $=0.57$ ); northern shoveler (Anas clypeata; adult $=0.51$ ); American wigeon (Anas americana; adult $=0.64$ ); and blue-uvinged teal (Anas discors; juv. $=0.29$, adult $=0.49$ ). Their findings were similar to data they summarized from the literature that were based on band recoveries. Mark-resighting studies require far fewer samples than are needed in banding studies, and can be used in studies of non-hunted species. Mark-resighting studies do require intensive field sampling to conduct the re-sighting. However, such re-sighting is under the control of the researcher, in contrast to band recoveries, over which the researcher has little control.

In glaucous-winged gulls (Larus glaucescens), Reid (1988) found $85 \%$ annual survival in adults, $80 \%$ in the second year, and $61 \%$ in first-year birds. Using these survival values and other population parameters to construct a Leslie matrix model, he calculated a lambda of 1.05 . This rate of population growth compared favorably to the observed rate of growth in the field.

Foster et al. (1992) examined the survival of 213 radio-fitted northern spotted owls in four study areas for $2-4$ years. The annual survivorship ranged between 0.67 to 1.00 with most between 0.80 to 0.94; no information on population persistence was provided. In Maryland, Bowman et al. (1995) provided survivorship data for 1-6-year-old bald eagles (their Table 1), and by using a deterministic life-table model predicted a finite population growth rate (lambda) of $5.8 \%$ per year. They found, however, that a simulated $12 \%$ decrease in minimum adult survival (from $83 \%$ to $73 \%$ ) eliminated population growth. Their review of the literature showed that their estimated survival rate exceeded those previously published. This study is important because it indicates that even a relatively minor change in survivorship can have substantial population impacts.

Bowman et al. (1995) also found that survivorship for bald eagles in Alaska was about 0.90 after the first-year, and survivorship withir! the first year was 0.71 . They used a deterministic life table to calculate a lambda of 1.02 ( $2 \%$ arınual population growth). They showed that their model was robust to changes in reproductive rates and annual survival rates for first-year eagles, but sensitive to changes in survival rates for older (after first-year) eagles (their fig. 2). Sensitivity analysis showed that lambda dropped to $<1$ when after first-year survival dropped to only $88 \%$; lambda dropped to about 0.93 when survival was lowered to $82 \%$.

Conway et al. (1995) conducted an experiment to evaluate the effects of removing nestling prairie falcons (Falco mexicanus) on the breeding population in an attempt to simulate the impacts of falconry. They removed 138 of 451 nestlings ( $31 \%$ of natality) from 20 territories during 1982-89, along with a control area. They found no overall difference in nesting success and productivity between treatments and controls, although treatments were lower than controls in 2 years of study. Their results suggested that intensive harvest of nestling prairie falcons may adversely affect some local population parameters, but harvests were sustainable and probably did not affect local population size. Because only about $0.2 \%$ of all prairie falcon natality is harvested annually in the United States, such a loss has no impact on population numbers or persistence (relative to the much higher level of harvest they simulated). This study is an excellent example of experimental evaluation of the impacts of loss of young, and indicates the resilience of raptor populations to such loss.

In his review of population limitations in birds of prey, Newton (1991) concluded that raptors have the most stable breeding densities among birds. He stated that breeding densities below those which would normally be supported by the food supply are held constant by shortages of nest sites. For raptors limited by available habitat, an increase in numbers could be achieved by either (1) increasing habitat availability, or (2) increasing the carrying capacity of existing habitat 
by increasing food supply and/or nest sites. Green and Hirons (1991) cautioned, however, that rapid population changes have been recorded in birds from many taxa and a wide range of body sizes. They noted that even populations of large species, which might be expected to have high survival rates and low rates of population change, can decline rapidly.

Rowley and Russell (1991) summarized numerous studies of demography in passerines. They showed that adult survivorship in passerines worldwide was seldom $>70 \%$. In North America, survivorship was usually from $50 \%$ to $69 \%$.

Martin (1995) summarized data from the literature on annual adult survival for North American Passeriformes and Piciformes. For shrub, grassland, and forested areas, survival ranged from 0.435 to 0.668 . Excavating cavity nesters had the highest survival $(0.668)$, whereas nonexcavating cavity nesters had the lowest survival regardless of vegetation type (0.435-0.444). Ground nesters $(0.569$ in forests, 0.569 in shrub/grasslands), shrub nesters $(0.529 ; 0.532)$, and canopy nesters $(0.609$, forest only) had survival rates that fell between the extremes of excavators and non-excavators. Martin also presented data on annual fecundity (defined as the product of numbers of broods and clutch size). Fecundity ranged from a low of 4.99 in excavators to a high of about 9 in non-excavators. Fecundity in ground, shrub, and canopy nesters ranged between 5.14 and 7.75. Martin concluded that variation in adult survival and fecundity was organized by nest site and most closely correlated with nest predation.

Swenson et al. (1986) summarized nest productivity (defined as the number of young fledged per occupied or active nest) and the reported population trend of 14 study populations of bald eagles. Study periods ranged from $5-15$ years and averaged 8 years. We correlated nest productivity and the associated population trend reported by Swenson et al. (1986:Table 11) and found a significant $(P=0.0012)$, positive correlation $\left(I^{2}=0.596\right)$. A graph of our analysis (Fig. 1$)$ indicates that productivity is a reliable measure of population trend in bald eagles. From Figure 1 it appears that populations have stable or increasing population trends when productivity is above 0.7 young fledged/nest; at 0.6 young fledged, both a stable and declining trend was observed. At productivity about $0.8-1.2$, populations were either stable or increasing; there was no clear level of productivity where populations were consistently increasing. Nevertheless, it appears that productivity $>0.8$ represents a stable or increasing population abundance. 


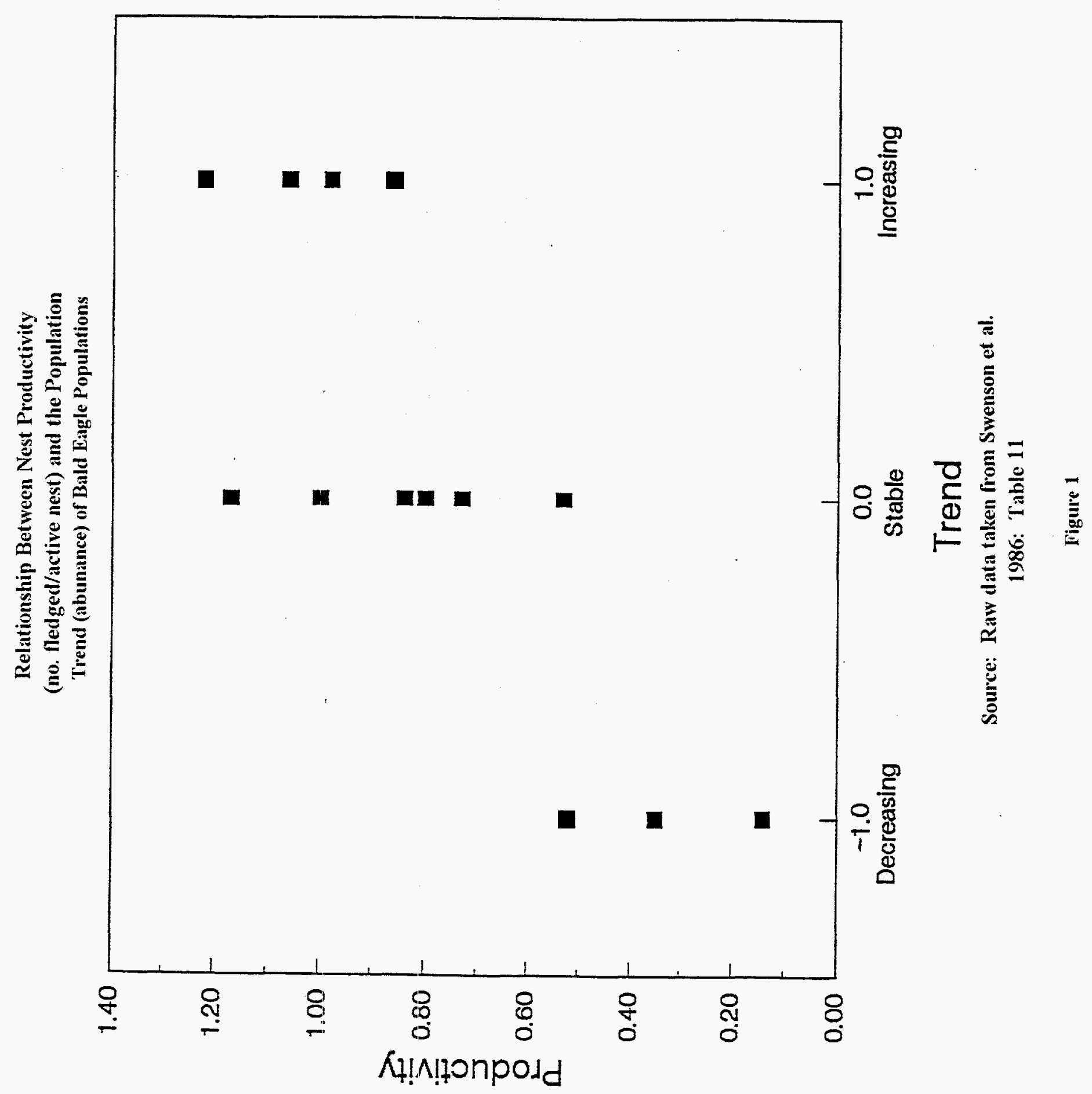




\section{Model Development: Examples for Wind-Development Applications}

To aid in providing general guidelines concerning the potential impacts of wind developments on bird populations, we conducted sensitivity analyses to determine the effects of survival of age classes on population growth rates. As detailed below, we gathered data from the literature on passerines, ducks, geese, gulls, and eagles. These analyses provide a first approximation of how populations of these types of birds respond to hypothetical changes in fecundity and survivorship. They can be used to help focus attention on species most likely to be adversely affected by changes in fecundity and survivorship.

These analyses use a Leslie matrix model (Caswell 1989). This model breaks the life cycle into stage or age classes and places the survival and fecundity rates for each class into a square projection matrix. This matrix can be multiplied by a vector containing current population sizes for each class to obtain the population sizes for the next year, i.e.

$$
n(t+1)=A * n(t)
$$

and thus projects population size into the future. This process may be repeated in order to make future predictions or to study the growth rate.

For example, a three-age class model would have a projection (or Leslie) matrix

$$
A=\mid \begin{array}{ccc}
F_{1} & F_{2} & F_{3} \\
P_{1} & 0 & 0 \\
0 & P_{2} & P_{3}
\end{array}
$$

where $F_{i}=$ fecundity of the ith age class (typically fledglings have $F_{1}=0$ ) and $P_{i}=$ the survival rate for the ith class, which may be multiplied by the vector of population sizes time $t$,

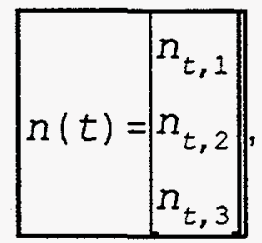

where $n_{t, i}$ is the size of the ith age class at time t.

Under certain regularity conditions on the matrix $A$ the population projections converge to a stable age distribution (Caswell 1989). The largest eigenvalue of the matrix A(eigenvalues solve an equation of the form $|A-\lambda| \mid=0$ ), is the population growth rate, lambda $(\lambda)$. If lambda $=1$, the population size is remaining constant, if lambda $>1$ then the population is increasing, and lambda $<1$ indicates a declining population size.

In the analyses, two age classes were used for passerines and ducks, three age classes for geese, seven for gulls, and eight for eagles. For passerines, ducks, and geese, models having 'reasonable' survival and fecundity parameters yielding lambda $=1$ were constructed. Values for fecundity and survival for age classes of eagles and gulls were modified from results in Bowman et al. (1995) and Reid (1988), respectively. These values resulted in lambda slightly larger than one ( 1.07 for eagles and 1.046 for gulls). 


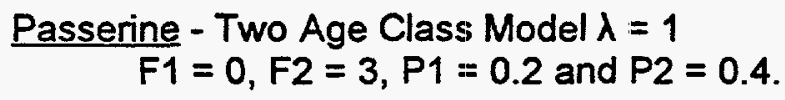

Duck - Two Age Class Model $\lambda=1$

$F 1=0, F 2=1.33, P 1=0.3$ and $P 2=0.6$. Goose - Three Age Class Model $\lambda=1$

$F 1=0, F 2=0, F 3=0.476, P 1=0.3, P 2=0.7$ and $P 3=0.9$.

Gull - Seven Age Class Model $\lambda=1.046$

$F 1=0, F 2=0, F 3=0, F 4=0.0174, F 5=0.43878, F 6=0.66172, F 7=0.71, P 1=0.607$, $P 2=0.8, P 3=0.853, P 4=0.853, P 5=0.853, P 6=0.853$ and $P 7=0.853$.

Eagle - Eight Age Class Model $\lambda=1.07$

$F 1=F 2=F 3=F 4=F 5=F 6=F 7=0, F 8=0.74, P 1=0.71, P 2=0.95, P 3=0.95, P 4=$ $0.95, P 5=0.88, P 6=0.88, P 7=0.88$ and $P 8=0.88$.

With the models in place, each survival rate parameter was allowed to vary from zero to one while the remaining parameters were held constant. The new value of lambda was calculated at each new value of the changing parameter. Once these data were obtained for each survival parameter, the results were plotted on a graph so as to see the different effects each parameter had on the population growth rate. This can be viewed as a way of expressing the sensitivity of lambda to the different survival parameters. It is important to distinguish between the true effect on the population (which is unknown), and the effect on lambda, which assumes the model is the "correct" model.

\section{Results}

\section{Passerines}

The curves for the passerine show that lambda is much more sensitive to changes in the juvenile survival rate than to changes in the adult survival rate (Fig. 2). Also, the juvenile survival rate curve has a very steep slope as the juvenile survival gets very small.

\section{Ducks}

The curves for the duck show that lambda is roughly equally sensitive to changes in the juvenile and adult survival rates (Fig. 3 ).

\section{Geese}

The nonadult age class survival rates seem to have little impact on the value of lambda (Fig. 4). For the adult age class, lambda is extremely sensitive to changes in the adult survival rate.

\section{Gulls}

Except for very small survival rates, the changes in the adult age class gives the largest change in lambda (Fig. 5). The other classes all have very similar curves.

\section{Eagles}

The situation for the eagle is very sirnilar to the situation for the gull, but even more extreme. There is great sensitivity of lambda to changes in adult survival rate (Fig. 6). 


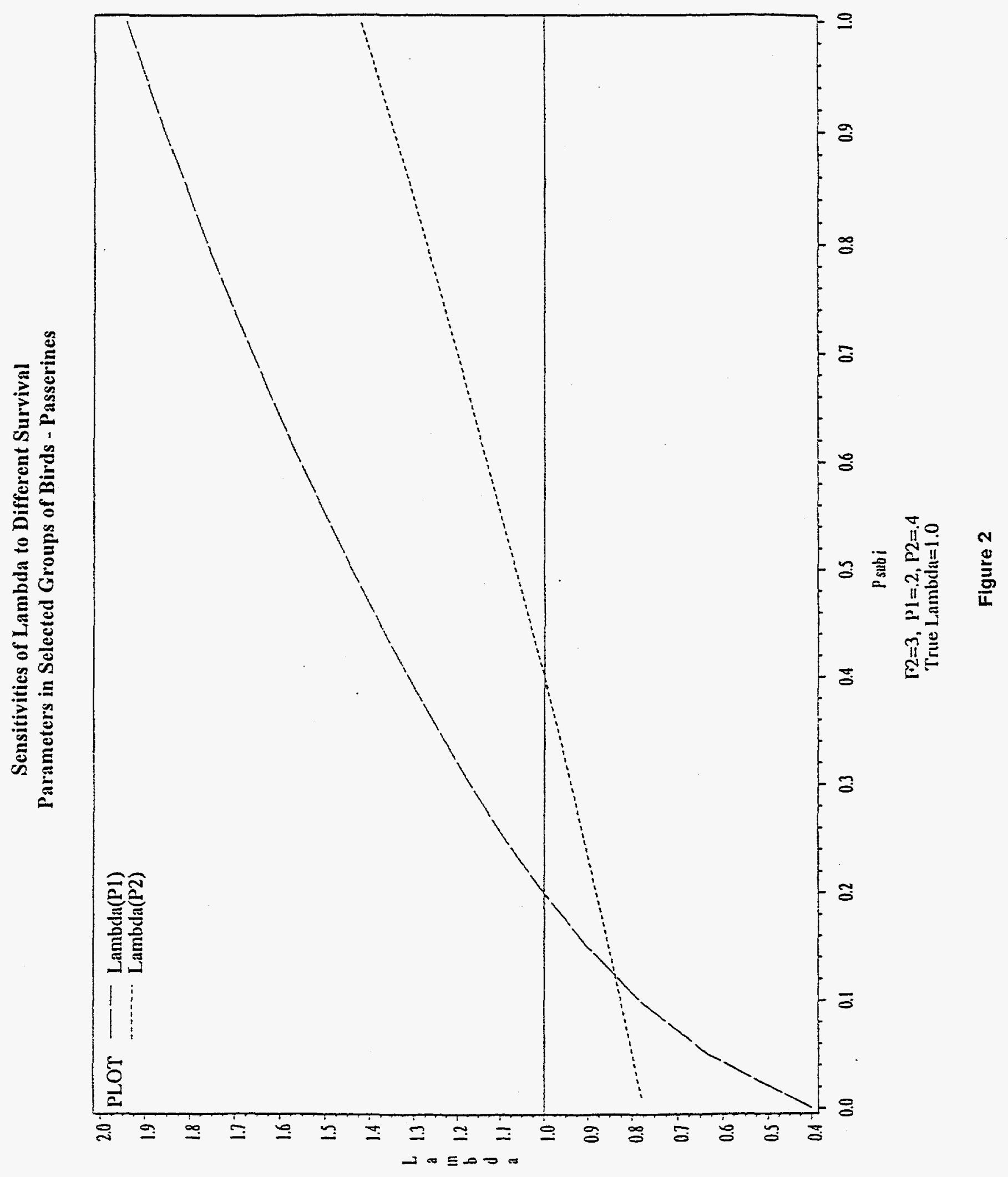


Sensitivities of Lambda to Different Survival

Parameters in Selected Groups of Birds - Ducks

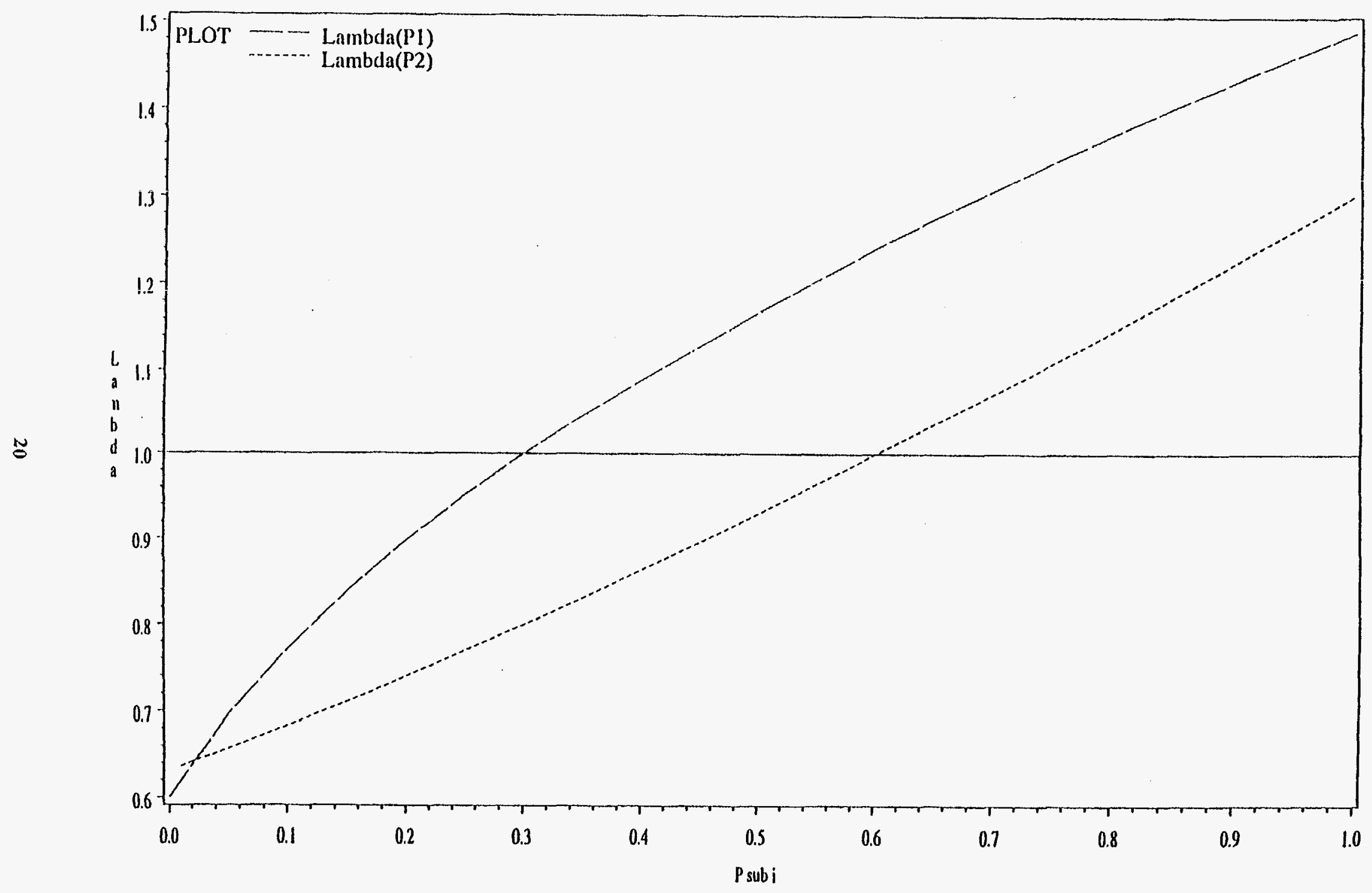

$\mathrm{F} 2=1.33, \mathrm{P} 1=.3, \mathrm{P} 2=.6$

True Lambdn=1.0

Figure 3 


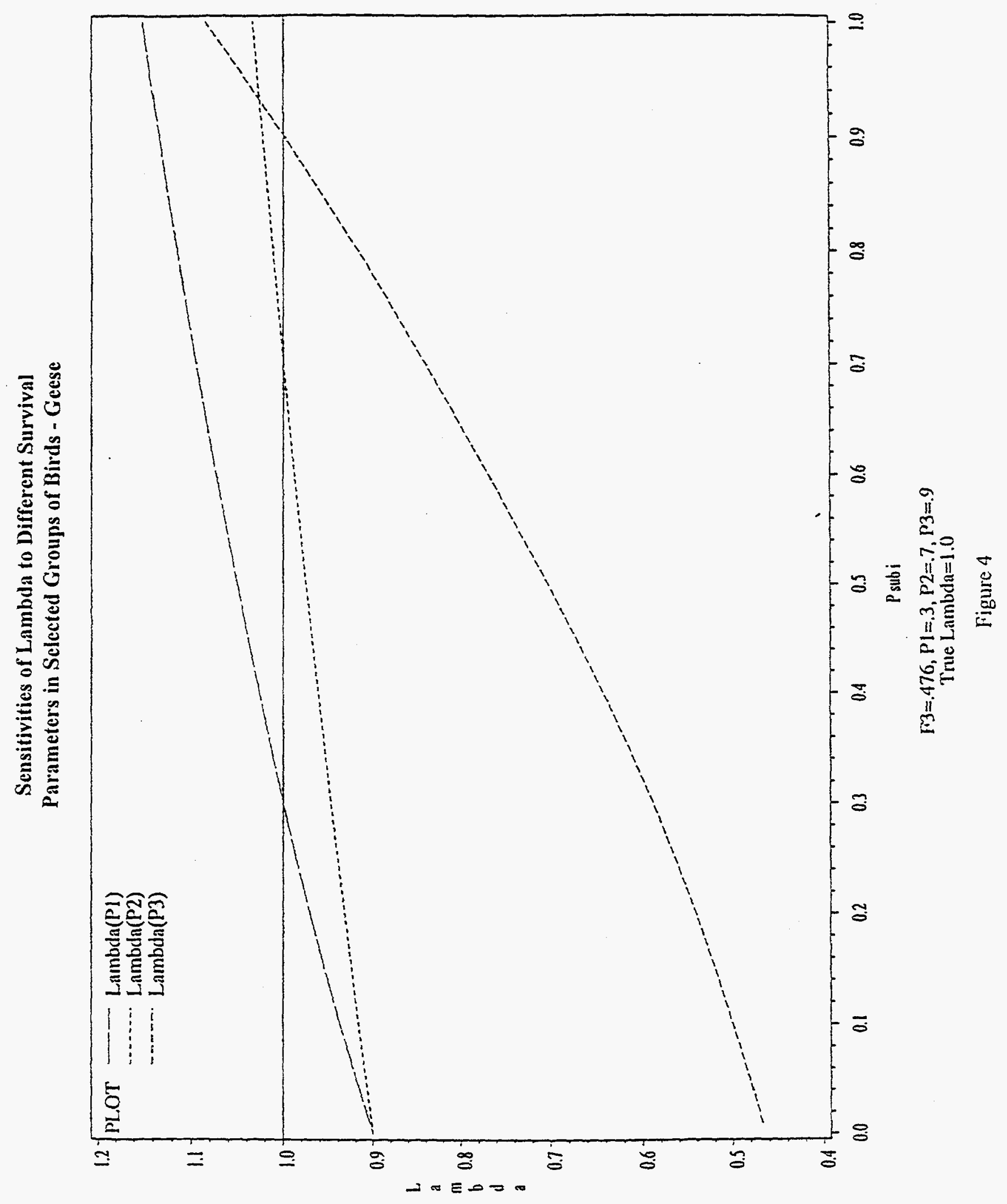


Sensitivities of Lambda to Different Survival

Parameters in Selected Groups of Birds - Gulls

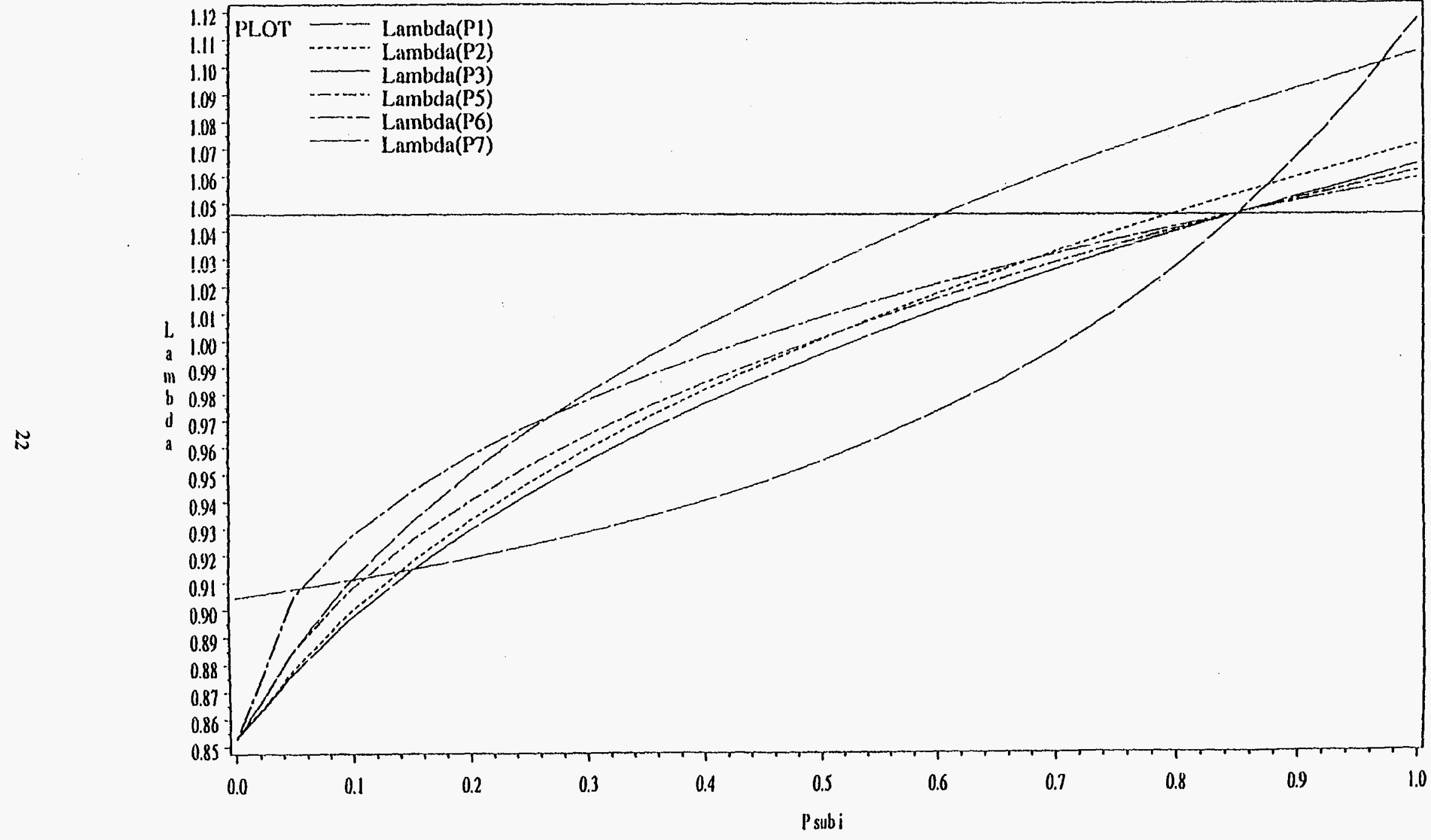

$\mathrm{P} 4=.0174, \mathrm{~F} 5=.43878, \mathrm{P} 6=.66172, \mathrm{~F} 7=.71$

$\mathrm{Pl}=607, \mathrm{P} 2=8.8 \mathrm{P} 3=.853, \mathrm{P} 4=.853, \mathrm{PS}=.853, \mathrm{P} 6=.853 \mathrm{p} 7=.853$

True Lambda $=1.046$

Note that Lambda(P3)=Lambda(P4)

Figure 5 


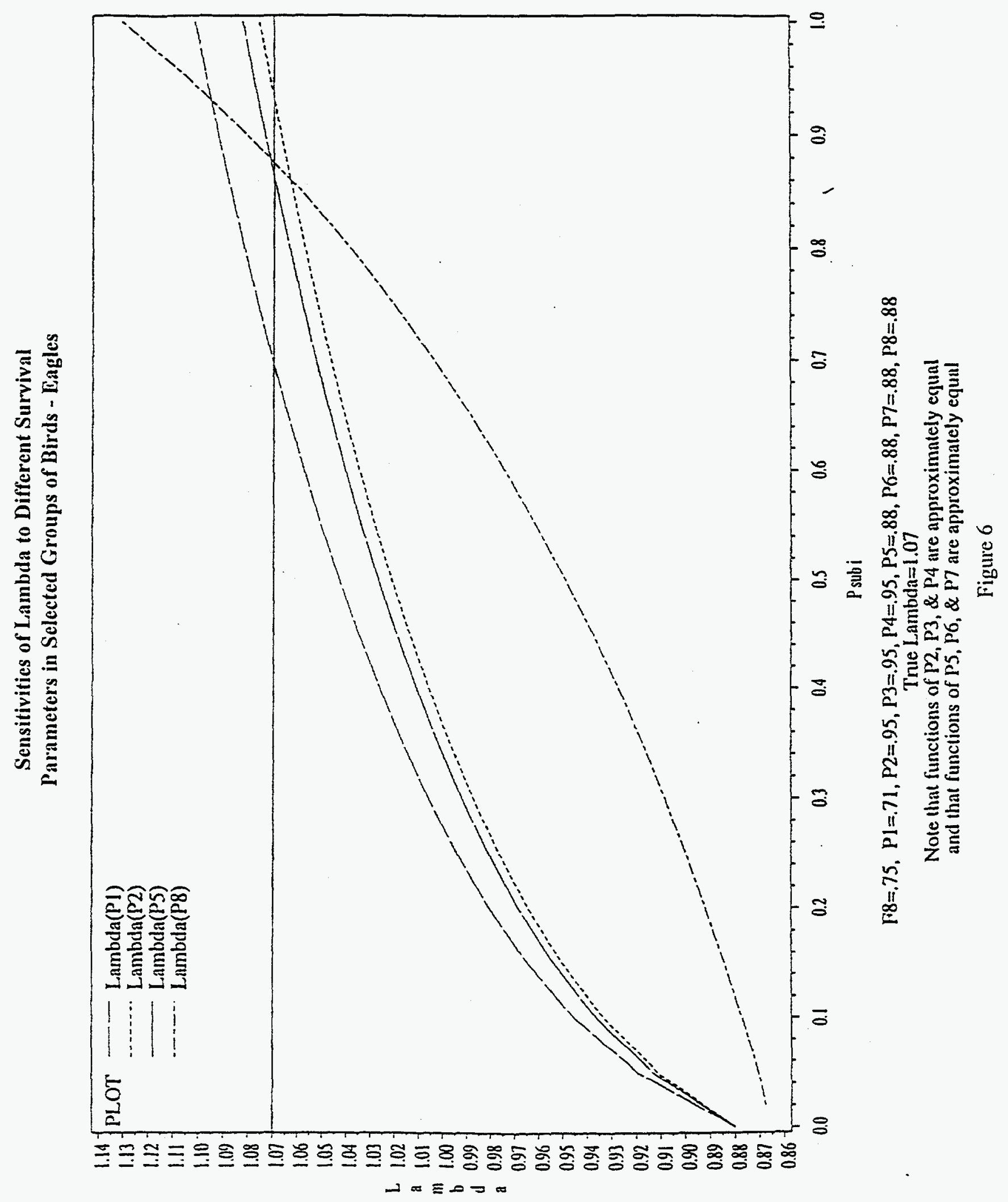




\section{Surrogates}

One of our objectives was to evaluate the use of surrogates, or indices, of survival and population trends. Using Martin's data (Martin 1995:Table 4) on adult survival and fecundity in Passeriformes (reviewed above), we found a highly significant $(P<0.0001)$ negative relationship $\left(r=-0.9731, r^{2}=0.9468\right)$ between adult survival and annual fecundity. This analysis indicates that fecundity might be a suitable surrogate for survival in passerines and woodpeckers. This does not imply, however, that fecunidity is a suitable indicator of abundance (i.e., increasing fecundity does not necessarily compensate for lower survival).

Territory occupancy has also been suggested as an indicator of population health (here, "health" refers to the stability of population size and adequate reproduction). For example, consistent interyear occupation of breeding territories (by the same or replacement individuals) has been accompanied by stable population levels in many species of raptors (e.g., Newton 1979, Swenson et al. 1986, Ferrer and Donazar 1996).

Newton (1979) noted that adult raptors will leave poor habitat (e.g., low food availability), often moving many kilometers in search of a suitable nesting site. In addition, raptors tend to change territories more often when nesting is unsuccessful. Thus, as a generality, constancy of territory occupancy seems to be an indicator of good habitat quality in raptors.

The number of nonbreeding, adult "floaters" in an area is an indicator of the general health of the bird population. This holds if territory availability is constant or increasing. Additionally, an increase in the age of first breeding, as well as an increase in adult aggression, are possible indicators of a population at or above carrying capacity (Newton 1979, Bowman et al. 1995). In long-lived species with delayed age at first breeding, such as in many raptors and some waterbirds, changes in survival rates have a greater effect on the population than changes of similar magnitude in reproductive rates. Thus, the use of reproductive success in long-lived species should likely be supplemented with other indicators, such as territory occupancy and floater individuals.

Conceptually, changes in the age ratios of a population are indicative of the current or likely nearfuture trend in population abundance. These ratios can be used in two primary fashions. First, the current ratio can be compared to literature values to approximate the likely status of the population under study. Second, ternporal changes in ratios track trends in population status. As the adult:subadult ratio nears 1, for example, we should determine why the population is becoming adult-dominated (e.g., low young production or survival). Swenson et al. (1986) found that the subadult:adult ratio was positively related to reproductive success in their study of bald eagles in the Greater Yellowstone Ecosystem.

The use of surrogates that we recommend here is not designed to determine the cause of population change. Rather, surrogattes are intended to only identify that change has occurred; whether or not such change is caused by wind development will usually require more rigorous research (e.g., field work and experimentation). Surrogates serve primarily as a coarse filter to help narrow the scope of subsequent research (see Temple 1985).

Temple (1985) suggested that the causes of a population decline might be readily identified by measuring productivity and comparing it with the values expected for the species of concern. If productivity seemed sufficiently high to balance the expected level of adult mortality, then the cause of the decline could be identified by elimination, as low adult survival. Survival rates were considered by Temple to be too difficult to measure directly given the time and money that is usually available. Green and Hirons (1991) criticized the Temple suggestion, stating that "expected rates" are highly suspect, both because of poor empirical data for most species, and 
because vital rates do not have fixed values. As evidenced by our sensitivity analyses (see above) and literature review, adult survivorship may be more important in some species.

Our review indicates, however, that productivity may serve as at least a crude indicator of the trend in population abundance. Recall that our analysis of the Swenson et al. (1986) bald eagle data indicated a significant $(\underline{P}<0.001)$ and moderately strong $\left(r^{2}=0.6\right)$ correlation between productivity and population trend. Further, our analysis of Martin's (1996) data showed a highly significant $(P<0.0001)$ and very strong negative $(r=-0.97)$ correlation between adult survival and annual fecundity. This result indicates that sampling fecundity is a reliable surrogate for adult survival. Both fecundity and survival can then be compared to published values for the same or related species as a first approximation of population status. Further, these estimates can be used in population models.

Beauchamp et al. (1996) documented declines in nest success for many species of prairienesting ducks between the 1930s and 1992. For the gadwall and northern shoveler, however, there were not concurrent declines in population abundance. The authors speculated that brood survival and survival throughout the annual cycle were more important indicators of population status than nesting success. Brood survival is, however, a measure of reproductive success. For birds in general, brood survival measures the number of young that were able to fledge from the nest and survive for a specific period of time (usually until independent from the adult).

Thus, it appears that Temple's (1985) suggestion to use productivity as a surrogate of survival may be appropriate. The points raised by Green and Hirons (1991) are valid, however, and we reiterate that such surrogates should only be used as first approximations of population status and as a means of prioritizing species for more intensive study.

\section{Conclusions: Development of An Analytical Framework}

From our review of factors known to influence population persistence, the following conclusions can be drawn: (1) It appears that there is too much uncertainty involving the minimum effective population size $\left(\mathrm{N}_{\mathrm{e}}\right)$ to use this index in evaluation of population responses to wind developments. In addition, even the 'minimal method' of calculation requires the estimation of numerous population parameters. (2) PVA analysis offers a useful framework for advancing understanding of the processes driving population responses to perturbations. Actual calculation of a viable population level, however, is far too complicated and subject to far too much variation to be useful in evaluating the responses of birds to wind developments. (3) The spatial structure of populations of concern should be considered. However, the practical difficulties of modeling more than one population, and including consideration of immigration and emigration, will usually prevent development of spatial-structured models. (4) Carefully evaluate how life-history parameters could interact to influence population persistence as a first approximation of the influence of wind developments on bird populations (e.g., sex ratio and productivity); this can be accomplished through the use of the Leslie matrix and related models. It also appears that surrogates of many of these factors can be developed as an additional first approximation of the status of a population. We present below a series of steps that can be used to develop a strategy for evaluating the influence of a project on a bird population.

\section{Hierarchical Framework}

Based on our review it seems that the appropriate hierarchial framework for evaluating population responses to perturbations is: 
1. empirical data

2. surrogates

3. model with available data (Leslie matrices).

A large set of empirical data is, of course, the optimal situation. Unfortunately, the time and funding necessary to obtain an adequate set of field data are seldom available for all of the factors of interest. Data that are available, however, feed into items \#2 and \#3, above.

Perturbation analysis of a model that captures the major dynamics of a population should be an integral part of a modeling exercise. Also, remember that the three items listed above are not mutually exclusive: as the quantity and quality of empirical data grows, our ability to develop good models and good surrogates increases.

As a subset of 3, above, Lebreton and Clobert (1991) summarized a hierarchical framework for modeling the dynamics of bird populations for conservation and management:

1. demographic models with constant parameters, with emphasis on sensitivity analysis

2. environmental variability and its effects on population growth rate

3. density-dependent models

4. models incorporating density dependence, spatial aspects, and various kinds of stochasticity.

From our review of the literature it is evident that we can seldom venture beyond Lebreton and Colbert's stage 3. Regardless, any modeling that is based on a data set with known variability will provide a useful evaluation of the potential response of a population to perturbations.

\section{Prioritization}

Most project locations are inhabited by many species of birds. As such, it will be necessary to select a subset of species for intensive study and modeling. To assist with the selection of species for study, we present the following simple criteria, in order of priority, for study:

1. Locally rare population of an overall rare species

2. Locally common population of an overall rare species

3. Locally rare population of an overall common species

4. Locally common population of an overall common species.

This hierarchy can be viewed in the following table, where "yes" means high priority or concern and "no" means lower priority or concern.

\begin{tabular}{|l|c|c|}
\hline & \multicolumn{2}{|c|}{ Species } \\
\hline Local Population & Rare & Common \\
\hline Rare & Yes (1) & No (3) \\
\hline Common & Yes (2) & No (4) \\
\hline
\end{tabular}

We may worry about \#1 and \#2 the rnost, although locally there is reason to worry about \#3. However, when priorities must be made, we suggest that this scenario is a reasonable starting point to determine allocation of resources. Alternatively, from a public and regulatory perspective, a rare species that is locally common (\#2) may be legally protected. From a biological perspective, this population may be integral to the survival of the species. Common 
species that are rare locally (\#3) may suggest that the area is on the periphery of the range or that some other parameter (e.g., habitat) is creating the problem, making the study of windpower impacts relatively unimportant.

Because of limited time and budgets, the results of these evaluations should be considered approximations of population status and longer-term persistence. It is imperative to continue to study the situation, should the wind development be approved, in order to improve the initial approximation. This would also improve the evaluation process in future impact assessments by providing additional empirical data.

\section{Acknowledgments}

We thank Holly Davis, Robert Thresher, and Karin Sinclair, National Renewable Energy Laboratory, for initiating and funding this study; William Kendall, Lawrence Mayer, Dale

Strickland, and Kenneth Wilson for reviewing the text; and Ann Oberg for assisting with analyses. 


\section{Literature Cited}

Arnold, T.W., and R.G. Clark. 1996. Survival and philopatry of female dabbling ducks in southcentral Saskatchewan. Journal of Wildlife Management 60:560-568.

Bart, J. 1995. Acceptance criteria for using individual-based models to make management decisions. Ecological Applications 5:411-420.

Beauchamp, W.D., R.R. Koford, T.D. Nudds, R.G. Clark, and D.H. Johnson. 1996. Long-term declines in nest success of prairie ducks. Journal of Wildlife Management 60:247-257.

Bellrose, F.C. 1980. Ducks, geese, and swans of North America. Stackpole Books, Harrisburg, Penn.

Bowman, T.D., P.F. Schempf, and J.A. Bernatowicz. 1995. Bald eagle survival and population dynamics in Alaska after the Exxon Valdez oil spill. Journal of Wildlife Management 59:317-324.

Boyce, M.S. 1992. Population viability analysis. Annual Review of Ecology and Systematics 23:481-506.

Buehler, D.A., J.D. Fraser, J.K.D. Seegar, G.D. Therres, and M.A. Byrd. 1991. Survival rates and population dynamics of bald eagles on Chesapeake Bay. Journal of Wildife Management 55:608-613.

Caswell, H. 1989. Matrix population models: construction, analysis, and interpretation. Sinauer Associates, Sunderland, Mass.

Caughley, G. 1977. Analysis of vertebrate populations. John Wiley and Sons, New York, N.Y.

Chu, D.S., J.D. Nichols, J.B. Hestbeck, and J.E. Hines. 1995. Banding reference areas and survival rates of green-winged teal, 1950-89. Journal of Wildlife Management 59:487-498.

Conroy, M.J., G.R. Costanzo, and D.B. Stotts. 1989. Winter survival of female American black ducks on the Atlantic coast. Journal of Wildlife Management 53:99-109.

Conway, C.J., S.H. Anderson, D.E Runde, and D. Abbate. 1995. Effects of experimental nestling harvest on prairie falcons. Journal of Wildlife Management 59:311-316.

Eberhardt, L.L. 1990. Survival rates required to sustain bear populations. Journal of Wildlife Management 54:587-590.

Foster, C.C. et al. (7 authors). 1992. Survival and reproduction of radio-marked adult spotted owls. Journal of Wildlife Management 56:91-95.

Ferrer, M., and J.A. Donazar. 1996. Density-dependent fecundity by habitat heterogeneity in an increasing population of Spanish imperial eagles. Ecology 77:69-74.

Getz, W.M., and R.G. Haight. 1989. Population harvesting: demographic models of fish, forest, and animal resources. Princeton University Press, Princeton, N.J.

Grant, P.R., and B.R. Grant. 1992. Demography and the genetically effective sizes of two populations of Darwin's finches. Ecology 73:766-784. 
Green, R.E., and G.J.M. Hirons. 1991. The relevance of population studies to the conservation of threatened species. Pages 594-633 in Perrins, C.M., J.-D. Lebreton, and G.J.M. Hirons, eds. Bird population studies. Oxford University Press, New York, N.Y.

Grier, J.W. 1980. Modeling approaches to bald eagle population dynamics. Wildlife Society Bulletin 8:316-322.

Haramis, G.M., D.G. Jorde, and C.M. Bunck. 1993. Survival of hatching-year female canvasbacks wintering on Chesapeake Bay. Journal of Wildlife Management 57:763-771.

Harris, R.B., and F.W. Allendorf. 1989. Genetically effective population size of large mammals: an assessment of estimators. Conservation Biology 3:181-191.

Henny, C.J., W.S. Overton, and H.M. Wright. 1970. Determining parameters for populations by using structural models. Journal of Wildlife Management 34:690-703.

Hill, W.G. 1972. Effective size of populations with overlapping generations. Theoretical Population Biology 3:278-289.

Hohman, W.L., R.D. Pitchert, J.L. Moore, and D.O. Schaeffer. 1993. Survival of female canvasbacks wintering in coastal Louisiana. Journal of Wildlife Management 57:758-762.

Jenkins, S.H. 1988. Use and abuse of demographic models of population growth. Bulletin of the Ecological Society of America 69:201-207.

Johnson, D.H. 1994. Population analysis. Pages 419-444 in T. A. Bookhout, ed., Research and management techniques for wildlife and habitats. The Wildlife Society, Bethesda, Maryland.

Krebs, C.J. 1985. Ecology: the experimental analysis of distribution and abundance. Third ed. Harper and Row, New York, N.Y.

Lande, R. 1987. Extinction thresholds in demographic models of territorial populations. American Naturalist 130:624-635.

Lande, R. 1988. Demographic models of the northern spotted owl (Strix occidentalis caurina). Oecologia 75:601-607.

Lande, R. 1995. Mutations and conservation. Conservation Biology 9:782-791.

Lebreton, J.D., and J. Clobert. 1991. Bird population dynamics, management, and conservation: the role of mathematical modelling. Pages 105-125 in Perrins, C.M., J.-D. Lebreton, and G.J.M. Hirons, eds. Bird population studies. Oxford University Press, New York, N.Y.

Lefkovitch, L.P. 1965. The study of population growth in organisms grouped by stages. Biometrics 21:1-18.

Leslie, P.H. 1945. On the use of matrices in certain population mathematics. Biometrika 33:183-212.

Lindenmayer, D.B., T.W. Clark, R.C. Lacy, and V.C. Thomas. 1993. Population viability analysis as a tool in wildlife conservation policy: with reference to Australia. Environmental Management 17:745-758. 
Lynch, M., J. Conery, and R. Burger. 1995. Mutation accumulation and the extinction of small populations. American Naturalist 146:489-518.

Mace, G.M., and R. Lande. 1991. Assessing extinction threats: toward a reevaluation of IUCN threatened species categories. Coriservation Biology 5:148-157.

Martin, T.E. 1995. Avian life histong evolution in relation to nest sites, nest predation, and food. Ecological Monographs 65:101-127.

McDonald, D.B., and H. Caswell. 1993. Matrix methods for avian demography. Current Ornithology 10:139-185.

Morrison, M.L., B.G. Marcot, and R.W. Mannan. 1992. Wildlife-habitat relationships: concepts and applications. University of Wisconsin Press, Madison.

Newton, I. 1979. Population ecology of raptors. Buteo Books, Vermillion, South Dakota.

Newton, I. 1991. Population limitations in birds of prey: a comparative approach. Pages 3-21 in Perrins, C.M., J.-D. Lebreton, and G.J.M. Hirons, eds. Bird population studies. Oxford University Press, New York, N.Y.

Nunney, L. 1992. Estimating the effective population size and its importance in conservation strategies. Transactions of the Western Section of The Wildlife Society 28:67-72.

Nunney, L., and D.R. Elam. 1994. Estimating the effective population size of conserved populations. Conservation Biology 8:175-184.

Reed, J.M., P.D. Doerr, and J.R. Walters. 1986. Determining minimum population sizes for birds and mammals. Wildlife Society Bulletin 14:255-261.

Reid, W.V. 1988. Population dynanics of the glaucous-winged gull. Joumal of Wildlife Management 52:763-770.

Reynolds, R.E., R.J. Blohm, J.D. Nichols, and J.E. Hines. 1995. Spring-summer survival rates of yearling versus adult mallard females. Journal of Wildife Management 59:691-696.

Rowley, I., and E. Russell. 1991. Demography of passerines in the temperate southern hemisphere. Pages 22-44 in Perrins, C.M., J.-D. Lebreton, and G.J.M. Hirons, eds. Bird population studies. Oxford University Press, New York, N.Y.

Ruggiero, L.F., G.D. Hayward, and J.R. Squires. 1994. Viability analysis in biological evaluations: concepts of population viability analysis, biological population, and ecological scale. Conservation Biology 8:364-372.

Shenk, T.M., A.B. Franklin, and K.R. Wilson. 1996. A model to estimate the annual rate of golden eagle population change at the Altamont Pass Wind Resource Area. Pages 47-54 in Proceedings of National Avian-Wind Power Planning Meeting II. National Wind Coordinating Committee, Washington, DC.

Smith, G.W., and R.E. Reynolds. 1992. Hunting and mallard survival, 1979-88. Journal of Wildlife Management 56:306-316.

Swenson, J.E., K.L. Alt, and R.L. Eng. 1986. Ecology of bald eagles in the Greater Yellowstone 
Ecosystem. Wildlife Monographs no. 95.

Temple, S.A. 1985. The problem of avian extinctions. Current Ornithology 3:453-485.

Wootton, J.T., and D.A. Bell. 1992. A metapopulation model of the peregrine falcon in California: viability and management strategies. Ecological Applications 2:307-321.

Wright, S. 1931. Evolution in Mendelian populations. Genetics 16:97-159.

Wright, S. 1938. Size of population and breeding structure in relation to evolution. Science 87:430-431. 


\section{Additional Readings}

Caswell, H., and M.C. Trevisan. 1994. Sensitivity analysis of periodic matrix models. Ecology 75:1299-1303.

Cochran, M.E., and S. Ellner. 1992. Simple methods for calculating age-based life history parameters for stage-structured populations. Ecological Monograph 62:345-364.

DeAngelis, D.L., and L.J. Gross, eds. 1992. Individual-based models and approaches in ecology. Chapman \& Hall, New York, N.Y.

Goodman, L.A. 1968. An elementary approach to the population projection matrix, to the population reproductive value and to related topics in the mathematical theory of population growth. Demography 5:382-409.

Manly, B.F.J. 1990. Stage-structured populations: sampling, analysis and simulation. Chapman and Hall, London, England.

Nichols, J.D., J.R. Sauer, K.H. Pollock, and J.B. Hestbeck. 1992. Estimating transition probabilities for stage-based population projection matrices using capture-recapture data. Ecology 73:306-312.

Plant, R.E. 1986. A method for computing the elements of the Leslie matrix. Biometrics 42:933939.

Vandermeer, J.H. 1975. On the construction of the population projection matrix for a population grouped in unequal stages. Biometrics 31:239-242. 